\title{
Dring Implications of commercial document delivery
}

\author{
By Bill Coons and Peter McDonald
}

\section{Criteria for substituting electronic journals for paper ones}

$\mathbf{T}$ he evolution of technology in the past decade has forced a radical reappraisal in the way academic libraries view their collections. This is especially true in light of the emerging definition of what constitutes a collection in the electronic environment. While libraries have long used document delivery via interlibrary loan as a means to provide access to materials not locally held, few of them have addressed commercial document delivery services from a broad collection development perspective.

\section{Uses of commercial document delivery}

Successful commercial document delivery services are transparent to users, contribute to the quality of scholarship and research, remain costeffective, and do not detract from a library's essential mission of collecting materials comprehensively for current or potential future use. There are four key areas where commercial document delivery ( $\mathrm{CDI})$ ) clearly impacts collection development. CDD may be used:

1) as a selection tool to assist in the decision to acquire new subscriptions. Annual document delivery requests for a specific title can be recorded and if the cost of CDD is more than half the subscription cost, a subscription should be considered;

2) in lieu of new subscriptions when CDD will improve access to journals which are too expensive or too select to justify purchasing;
3) in lieu of current subscriptions-canceling low-use, high-expense titles (after historical value is considered). Shifting the cost from purchasing (and processing) a journal title to purchasing journal articles should be done only if significant savings result; and

4) to supplement current interlibrary loan service in cases requiring immediate delivery, for selected items at the bindery, or for those requests where "fair use" has been exhausted.

\section{Commercial document delivery in academic libraries: Caveats}

Financial pressures and the drive for leaner and meaner organizations that can flourish in an era of change have meant that even major research libraries cannot be as all-encompassing as they once were in their collection development efforts. The nature of research collections is changing: librarians are looking beyond ownership and considering access to external electronic resources and commercial document delivery services as a means to augment onsite collections.

Research libraries are obligated to protect a broad and deep historical record of intellectual activity for researchers of future generations, and selectors must ensure that the historical record of current, little-used journals surviveseither at their library or at other research institutions which can be trusted to preserve the record indefinitely (journals that are considered marginal today may be the most sought after by researchers in the future). There are legitimate concerns regarding the effects of CDD on the long-term ability of libraries to provide access to information needed for instruction and research: if unwisely applied, the use of CDD 
to replace subscriptions could do significant long-term damage to the research value of a collection, and if an institution embarks on a major program of substituting document delivery for subscriptions, they should first seek firm agreements with peer institutions ensuring that the subscriptions canceled in one location will be preserved elsewhere. Close monitoring and formal reviews are also necessary to assure costeffectiveness and a collection's historical integrity.

Selectors and reference librarians must consider the needs of patrons and address issues involving access equity, costs and payment strategies, staff training, cross-divisional cooperation (among acquisitions, ILS, reference, technical services, circulation, and selectors), and timely communications with both staff and patrons before CDD is implemented.

\section{Criteria and guidelines for selectors}

Selectors should consider the uses of the collection and the trends in university research and education as they evaluate either canceling existing subscriptions or not entering new ones. CDD should not be considered as a fullscale replacement for traditional ILS and subscriptions to highly valued and much-used journal titles should not be replaced by CDD. There must be communication between selectors and their constituencies before any effort is made to replace traditional sources in favor of CDD.

There are several criteria which a selector can use to determine if CDD is an appropriate substitute for print-based journal subscriptions. Three primary criteria are use, costs, and historical value; secondary criteria include language, geography, publisher type, accessibility, and copyright and licensing.

\section{Primary criteria}

Use:

- immediacy of need

- amount of use

- importance of browsing

- political implications (e.g., is it likely to adversely affect a powerful department chair?)

\section{Costs:}

- Selectors need to contrast and balance the real and hidden costs of a subscription against CDD. For instance, does it cost more money to buy a subscription to a seldom-used title than to get copies of selected articles? CDD becomes attractive when there is low journal use and high subscription costs. It should be noted that subscriptions involve various "hidden" costs inclucling cataloging, processing, binding, and shelving. Indeed, the storage costs for shelf space should be included, as should the staff costs of processing and accounting.

- For CDD to be economically effective, total CDD costs for all requests for one title must be less than the total for the real and hidden costs of a journal subscription (within a prescribed time period). Another way of looking at this is that if the total costs of CDD for one title are less than the cost of a subscription, the need for maintaining a subscription to that title should be reevaluated.

\section{Historical value:}

- Selectors should consider if a title being canceled is being archived in a sister institution. The length of a serial run should be known and whether or not it can be reasonably assured of an institution's commitment to maintaining a subscription in perpetuity.

- Relevancy of the subject matter to the current and long-term research and educational needs of the university.

- Uniqueness and value of the title (is it central to a discipline or peripheral?).

\section{Secondary criteria \\ Language:}

- Selectors for predominately English-language collections might use CDD to support their minimal foreign language material needs.

\section{Geography:}

- CDD may not be as appropriate for a collection that concentrates on one area, region or country.

\section{Publisher type:}

- As a cost-saving approach, CDD may be more appropriate as a substitute for higher priced titles. Of the four major types of publishers available to libraries, the most expensive are the commercial operators and the least are government agencies. In between lay the society/organization (expensive) and the university (relatively inexpensive) publishers.

\section{Accessibility:}

- It should be ascertained how else a journal title might be accessed. Is it available electronically? Is it part of a CD-ROM system such as UMI's ProQuest ABI/Inform? 


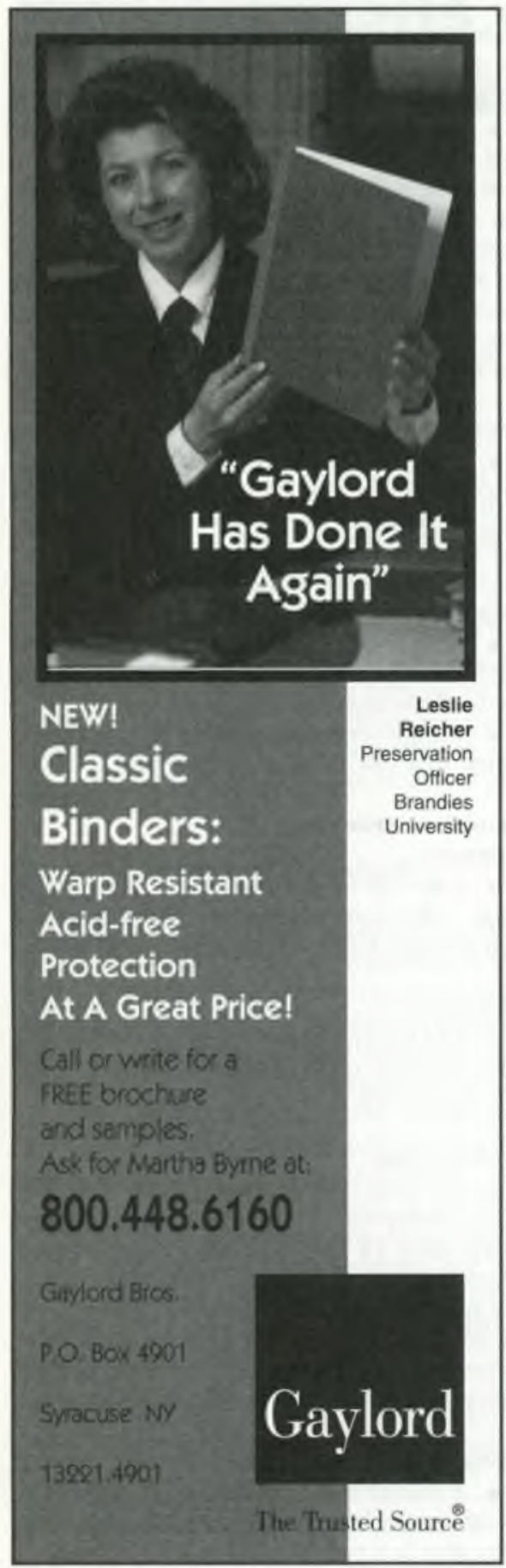

Copyright/Licensing:

- It is assumed that any library will only use those CDD services which are cognizant of and responsible for copyright issues. Selectors must keep these issues in mind and be aware of possible problems.

\section{Payment}

In an ideal world individuals would not have to incur direct costs for using library resources and services. While there are important philosophical questions in this regard, prudent use of a library's limited funds suggests that academic libraries must find a common ground with regard to payment. CDD could be paid for through centralized funds, as many libraries now subsidize ILS, and selectors could use some of their regularly allocated acquisition funds to purchase materials through CDD. In this model, cost of staffing to provide for CDD and ILS would remain part of general operating expenses.

Other payment models are possible, and to maintain control over the cost of CDD it makes sense to implement one or more of the following user fee policies:

- Users pay additional costs for rush services.

- Users fund a portion of CDD either by paying a low flat fee for each article requested or by paying costs over a certain amount.

- If the cost of a document is more than a predetermined amount, users should be informed of the price and asked if the item is important enough to justify the cost (of course, this is practical only if the CDD request is mediated). Another method might involve a question on a request form used by the patron which asks the patron to check a box indicating the maximum amount of money that should be spent to acquire the article.

Whatever mechanism is used to purchase documents, the billing and accounting paperwork must be kept to a reasonable level. Consideration must be given to the impact on staffing levels of ILS and/or acquisitions should document delivery requests increase the overall amount of work.

\section{Checklist of commercial document delivery issues}

Before embracing or rejecting CDD, academic libraries might answer these questions:

A) What is your library's relationship to and philosophy regarding CDD services? 
- Should your library begin to rely on CDD services?

- Is there sufficient in-house infrastructure to rely on CDD services?

- To what extent should your library rely on CDD services?

- How can your library better explore new document delivery technologies?

\section{B) What CDD options are available?}

- Which vendors provide on-demand services for the purchase of individual journal articles?

- Which journals are offered by CDD vendors?

- What delivery services are provided?

- What are the comparative costs of different vendors?

- Which vendors are being used now by peer institutions?

- What have been other institution's reactions?

C) What is the relationship of CDD services to selectors and the collections?
- Could selectors begin to use CDD services as a substitute for certain subscriptions?

- Under what circumstances, and with what criteria, should selectors make these decisions?

- Should selectors use CDD services as a selection tool, especially for new titles?

\section{D) Who should pay for CDD services?}

- Should CDD services be funded from a single materials budget?

- Should CDD services be self-supporting and funded directly by users or by departments?

- Should CDD services be supported from a variety of funding sources?

E) What are the effects of CDD on the longterm ability of academic libraries to provide access to information needed by users for instruction and research?

- What would be the effects of a substitution of delivery services for subscriptions on the long-term capacity of the library to support local long-term instruction and research needs?

- If there are any detrimental effects, what steps might be taken to minimize them?

\section{ACRL Auction}

In support of the ACRL Leadership Endowment OCLC \& ABPC are offering:

\section{$A B P C$ CD-ROM}

American Book Prices Current is offering an updated CD-ROM with auction sales reported in $A B P C$ (1975-1994). Covering 19 volumes in over a half million records, the CD contains the sales of autographs, manuscripts, documents, books, maps, and broadsides with sales information from auction houses worldwide. Provides comprehensive index and key-word searching as well as bibliographic information.

\section{Regular Rate: $\$ 2,000$ \\ Minimum bid: $\$ 600$}

\section{OCLC FirstSearch}

Online Computer Library Center, Inc., is offering a six month subscription to the FirstSearch base package. Includes single port access to the following databases: WorldCat, ArticleFirst, ContentsFirst, FastDoc, MEDLINE (USA only), ERIC, and GPO Monthly Catalog.

\section{Regular Rate: $\$ 2,750$} Minimum bid: $\quad \$ 750$

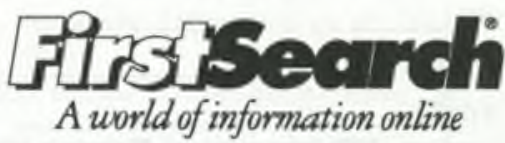

\section{How to Bid:}

To place a bid call Jack Briody at the ACRL office, (800) 545-2433, ext. 2516, or e-mail: jack.briody (9)ala.org. Bids will only be accepted at $\$ 75$ increments.

Bidding ends 4:00 p.m. CST, Dec. 15, 1995. 


\section{The world of Metals and Materials just got a little smaller.}

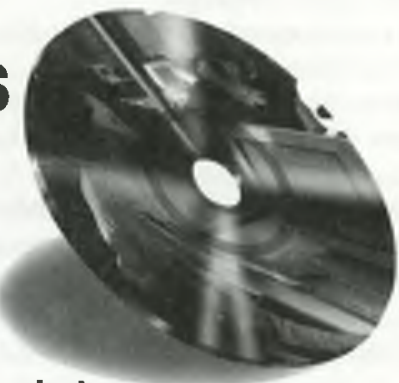

\section{Easy to navigate.}

Get instant access (with no time limits or penalties.) Switch effortlessly between two extremely flexible search methods. Search conference papers by title, location, sponsor or year! Sort your search by title, journal, author, or date! Search for patents! Browse informative abstracts.

\section{The world is on your CD. And it's FREE.}

Take advantage of our terrific offer and explore the world of metals and advanced materials. Call 1-800-336-5152 ext.620 today for your FREE 30-day trial of the METADEX Materials Collection or Advanced Materials CD-ROMs. Or fill out and send in the coupon below.

\section{For technical questions, call:}

Mark Furneaux, ASM

Tel: (216) 338-5151

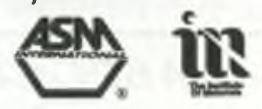

Actual OnDisk CD not shown. Materlals Intarm ation is a joint service of ASM international and the Institute af Materials. The Institute of Waterials is registered with Charity \# 269275 .

YES! I think the world of your offer!
I'd Ifike a FREE 30-day trial. Please send me details on:
METADEX Materials Collection CD-ROM.
NAME
COMPANY NAME
ADDRESS
CITY
COUNTRY
PHONE (
Send to: ASM International, Materials Information
C. Landefeld, Materials Park, Ohio 44073-0002




\section{Conclusion}

Implementation of CDD has much to offer financially strapped academic libraries and should be vigorously explored. With a coherent CDD policy, most selectors and collection development personnel will find it helpful in providing a value-added service to users. Implementation need not, initially, be systemwide, but might profitably be explored by smaller units with genre or subject selectors. If enough people within an institution elect to use CDD, a centralized mechanism to coordinate the process may be necessary.

In the long term, academic libraries should examine whether emerging technologies might obviate the need for CDD altogether, notably in the arena of networked user-initiated ILL. Libraries should seek out the expertise of partners on campus (such as campus stores, print shops, computing centers, etc.) to examine the opportunities offered by emerging technologies.

Authors note: This article is based on an internal document prepared for the Cornell University Library. The authors wish to thank these colleagues for their significant contributions: G. David Brumberg, Phil Dankert, Patricia O'Neill, and Scott Wicks.

\section{Resources}

Braid, J. Andrew. "Electronic Document Delivery: A Reality at Last?" ASLIB Proceedings 45 (June 1993): 161-66.

Boethem, Jeri Van. "Whether by Byte or by Tome, Buying Information Is Acquisitions." Library Acquisitions: Practice \& Theory 17 (fall 1993): 359-62.

Higginbotham, Barbara Buckner, and Sally Bowdoin. Access Versus Assets: A Comprebensive Guide to Resource Sharing for Academic Libraries. Chicago: ALA, 1993.

Jackson, Mary E. "Library to Library: Iinterlibrary Loan, Document Delivery and Resource Sharing." Wilson Library Bulletin 68 (September 1993): 76-78.

Khalil, Mounir. "Document Delivery: A Better Option?" Library Journal 118 (February 1, 1993): 43-47.

\section{PROVE Y OUR POINT}

Invest in your collection with OCLC/AMIGOS Collection Analysis Systems.

Ask for a FREE Collection nalysis $\mathrm{CD}$ demo set for results you can see!

\section{塞宣} CII, INC

४ Support accreditation studies

- Compare rour collection to more than 2.300 institutions

- Measure effectiveness of rour collection development policy

- Justify budget requests

- Evaluate resource sharing opportunities

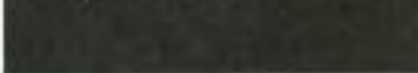

amigos@amigos.org $\quad 800 / 843-8482 \quad 214 / 851-8000$
Kurosman, Kathleen, and Barbara Ammerman Durniak. "Document Delivery: A Comparison of Commercial Document Suppliers and Interlibrary Loan Services." College and Research Libraries 55 (March 1994): 129 39.

Lewis, Martha. "Document Delivery Vendors: Benefits and Choices." Serials Librarian 23 (1993): 217-24.

Roberts, Elizabeth P. "ILL/Document Delivery As an Alternative to Local Ownership of Seldom-Used Scientific Journals." Joumal of Academic Librarianship 18 (March 1992): 30-34.

Zipp, Louise S., and Kathryn Kjaer. "An Alternative to Ownership of Scientific Journals in University Research Library Collections." In Mary B. Ansari, ed. Frontiers of Geoscience Information, Proceedings of the 24 th Meeting of the Geoscience Information Society, St. Louis, Missouri, 6-9 Nonember 1989, Volume 20, pp. 141-56. 